\title{
Energetic Materials, Part II: TNT and Other Military Explosives
}

By the end of the 19th century, Alfred Nobel's invention of straight dynamite had turned the unstable and dangerous nitroglycerin into a usable energetic material. Dynamites had almost completely replaced black powder for blasting applications, and in the process had made Alfred Nobel one of the world's richest men. However, many improved energetic materials came into use over the next few decades, especially with the great demands required when explosives were used for military purposes.

Nitroglycerin, and therefore dynamite, is very insensitive when frozen. This fact allowed for relatively safe shipping of the material when packed in ice, but it also made application difficult in everyday use, since its freezing temperature (only $52^{\circ} \mathrm{F}$ ) can occur nearly any time during the year. Not only did frozen dynamite fail to detonate, but neither could users punch a hole in it to add a blasting cap, or tamp it into a borehole. This meant that dynamite had to be thawed before use-and careless thawing methods led to many accidental detonations.

Dynamite made with
ethylene glycol has been
stored in the open at
Point Barrow, Alaska,
for four years without
freezing.

By 1907 , a low-freezing dynamite was developed by adding 20-25\% liquid isomers of TNT (described below) to the nitroglycerin; the TNT was later replaced by a nitrated solution of sugar in glycerin. In 1911 the nitration product of the glycerin polymer, diglycerin, began to be manufactured-tetranitrodiglycerin-which substantially reduced the freezing point when mixed with nitroglycerin. The availability of synthetic ethylene glycol in 1925 provided the solution still used today. Dynamite made with ethylene glycol has been stored in the open at Point Barrow, Alaska, for four years without freezing.
The nitroglycerin content of dynamite also made the material expensive and still somewhat unstable. In 1867 Swedish entrepreneurs began substituting ammonium nitrate in part for nitroglycerin. Nobel himself created "extra dynamites" containing $20-60 \%$ ammonium nitrate in a gelatin form. For about the next two decades, researchers worked at developing nongelatinous mixtures with ammonium nitrate, but ammonium nitrate is too hygroscopic. However, in 1885 the American R.S. Penniman found that he could avoid the water-absorption problem by coating ammonium nitrate with a small amount of paraffin just before use.

From then on, ammonium-nitratecontaining explosives became very popular. Ammonium nitrate has a low explosion temperature-a valuable property, since many of these materials were used for blasting mines, where methane gas and coal dust could ignite in a disastrous secondary explosion. Cooling agents, such as common salt or ammonium chloride, were also added to the compounds to further reduce the explosion temperature.

In 1875 Alfred Nobel sought to develop a cohesive energetic material that would detonate underwater. According to one account, Nobel hurt his finger and sealed the wound with collodion, a gummy solution of nitrocellulose dissolved in ether that hardened into a clear, flexible film. The pain of the injury kept Nobel from sleeping, and he went to his laboratory. Once there, he decided to mix nitroglycerin with collodion to see what would happen. After the solvent evaporated, a tough plastic material remained, which he called "blasting gelatin."

He found that he could add $7-8 \%$ pure gun-cotton (nitrocellulose) to nitroglycerin for the same effect; even lower percentages of gun-cotton made the viscosity decrease, allowing Nobel to add other active ingredients. He called the doped mixtures "gelatin dynamites." Gelatin dynamites had high water resistance and greater blasting power than straight dynamites, resulting from the higher density of the material and also its plasticity (which allowed complete packing of a borehole). Water gels remain extremely popular even today, composing more than $10 \%$ of all industrial explosives used in the United States. They are the most powerful industrial explosive, achieving detonation velocities up to 8,000 $\mathrm{m} / \mathrm{s}$.

Nobel had been working with nitrocellulose for several years, as had many other explosives researchers. As early as 1833 French chemist Henri Braconnot concocted a flammable nitric acid ester of starch, and Theophile J. Pelouze announced the explosive properties of nitrated paper in 1838. German-Swiss chemist Christian Schoenbein first created nitrocotton, or gun-cotton, in 1845 by dipping cotton in a mixture of sulfuric and nitric acids, then washing the treated cotton with water to remove the acids. Nitrocotton was two to four times as effective as black powder for blasting in mines, but it proved too energetic a substance to be used as a military weapon propellant, as Schoenbein had hoped.

In 1860 Major E. Schulze of the Prussian army adapted the nitrocellulose process by adding small pieces of wood to nitric acid, washing away the acid, then impregnating the treated wood chips with potassium and barium nitrates (to provide oxygen for burning the parts of the wood that had not been completely nitrated). Schulze's wood powder proved useful as a propellant for shotguns, but was too violent for most rifles and cannon.

In 1884 French chemist Paul Vieille partially dissolved nitrocellulose in a mixture of ether and alcohol until it turned into a gelatinous mass, which he rolled into sheets. After drying, these sheets could be cut into flakes. After the solvent evaporated, the hard and dense material remaining was similar to horn, and could be used as a propellant for all kinds of guns. This was the first example of "smokeless powder."

Nobel introduced his own smokeless powder, "ballistite," in 1887 , by mixing $40 \%$ of a more soluble type of nitrocellulose (which had a lower nitrogen content) with $60 \%$ nitroglycerin. This type of smokeless powder continued to be popular for 75 years. The British ignored Nobel's patent on the material and developed their own similar products under the general name of "cordite."

In the United States, E.I. du Pont de Nemours \& Co. first marketed a smokeless powder in 1909, which proved to be the most important type used by the Allies in 
World War I. Made from a low-nitrogen nitrocellulose, called pyrocellulose, du Pont's powder used a small amount of diphenylamine as a stabilizer. After the grains were formed and dryed, a coating of graphite was added.

Nitrostarch, similar to nitrocellulose, also attracted some attention when in 1905 it was available in a stable form. Nitrostarch explosives are similar to the straight dynamites used then, except that nitrostarch replaces the nitroglycerin. Though nitrostarch explosives have a relatively low strength, mediocre water resistance, and cannot be transformed into gels, they still proved useful because they did not produce the severe headaches familiar to handlers who allowed other nitroglycerincontaining materials to contact their skin.

\section{Military Explosives}

Military explosives must meet different criteria than industrial explosives-they must have smaller critical diameters, higher densities, higher detonation velocities, and higher explosion pressures. While most industrial explosives are made to be free flowing to allow filling boreholes, most military explosives are rigid solids. In addition, military explosives must be insensitive to shock and friction, and must be unlikely to detonate from small arms fire. Some types must have nearly unlimited resistance to water; others must be stored under potentially adverse conditions for long times without deteriorating. They must be fired in projectiles or dropped in aerial time bombs without premature detonation.

Most energetic materials for military purposes were developed in the 19th century, but the first extensive use did not take place until the Russo-Japanese War in 1905. Until this time, weapons had primarily

\section{TNT was used \\ in the dye industry before it was first detonated in 1904.}

used black powder, but picric acid began to be used instead. Picric acid was first prepared in 1771 by Pierre Woulfe (and for the next century was used principally as a yellow dye!), until German chemist Hermann Sprengel showed in 1871 that it could be detonated. In 1885 French chemist Eugene Turpin showed how picric acid could serve as a bursting charge when it was meltpoured into artillery shells. Picric acid was used extensively in World War I, but the U.S. Army and Navy used even greater amounts of trinitrotoluene, or TNT.

Though discovered in 1863, TNT was not used extensively in artillery shells until just before World War I, when an inexpensive process for nitrating toluene allowed TNT to replace picric acid. TNT became as important to military explosives as nitroglycerin had been to industrial applications.

TNT had also been used in the dye industry before it was first detonated in 1904 . As a military explosive, TNT is valuable alone, but it can also be safely melted and cast because of a large difference between its melting point and its decomposition temperature. TNT is difficult to cast without air holes, but this can be overcome by adding about $40 \%$ trinitroxylene (TNX) to the mixture. TNT can also be mixed in slurries with other energetic materialsespecially dispersed with powerful granular explosives such as RDX (cyclomethylenetrinitramine), HMX (cyclotetramethylenetetranitramine, also known as high-melting explosive or Her Majesty's explosive), and PETN (pentaerythritol tetranitrate), which cannot themselves be melted safely.

Shortages of TNT during World War I forced the creation of less-satisfactory compounds, such as mixtures of TNT with ammonium nitrate (known as amatols). The mixtures most commonly used were $80 \%$ ammonium nitrate and $20 \%$ TNT, or $50 \%$ of each. These performed nearly as well as pure TNT and were much less expensive. Amatols were used in World War II for aerial bombs as well as artillery shells.

In World War II several other new explosives came into use, primarily RDX, PETN, and EDNA (ethylenediaminedinitrate)all with TNT (normally $40-50 \%$ ). Some compounds also included aluminum powder, which provided a large amount of heat accompanying its oxidation. These new compounds offered extremely high shattering powers. For instance, the compound of $60 \%$ RDX with $40 \%$ TNT, called cyclotol, yields a detonation pressure of about four million pounds per square inch.

In the post-War years, industrial explosive development, which had lagged during the War, began to produce many new developments for commercial applications, such as fertilizer-grade ammonium nitrate (FGAN)-made memorable by a catastrophic explosion of a manufacturing plant in Texas City, Texas, in 1947-and its mixtures with fuel oil and in prills and slurries.

Ironically, when Alfred Nobel first created dynamite in 1866, he had believed that the proliferation of military explosives would make all warfare obsolete because the death and destruction would be too horrible to risk.

KEVIN J. ANDERSON

\section{If your library doesn't subscribe to Journal of Materials Research, don't you think it should?}

\author{
Your colleagues will benefit from JMR's \\ - new monthly publication schedule \\ - distinguished editorial leadership \\ Walter L. Brown, Editor in Chief \\ Shigeyuki Sōmiya, Assoc. Editor \\ (Japan) \\ Werner L. Lutze, Assoc. Editor \\ (Europe)
}

\author{
- interdisciplinary emphasis \\ - accessibility-JMR is referenced in Chem \\ Abstracts, Current Physics Index, Science \\ Citation Index, Metals Abstracts, INSPEC, and \\ many other key bibliographic systems.
}

and You will benefit by always having a "backup" in case you loan out your copy of JMR.

Tell your librarian about Joumal of Materials Research! 